\title{
COVENANTS CONTRATUAIS DE RATING: UMA ANÁLISE DE ASSOCIAÇÃO COM AS BOOK-TAX DIFFERENCES
}

\author{
Alexia Sene Ibrahim ${ }^{1}$ \\ Josilene da Silva Barbosa ${ }^{2}$ \\ Patrícia de Souza Costa ${ }^{3}$
}

- Artigo recebido em: 20/09/2019 -- Artigo aceito em: 04/02/2020 --' Segunda versão aceita em: 19/02/2020

\section{RESUMO}

Devido à relevância dos ratings para o custo da dívida e obtenção de recursos, os gestores podem ser motivados a solucionar questões que interferem negativamente no rating. Nesse sentido, uma vez que a book-tax differences (BTD) podem impactar negativamente no rating, acredita-se que os covenants contratuais de rating também possam interferir nas BTDs, pois os gestores poderão tomar decisões de forma a resultar em BTD que favoreçam a classificação de crédito. Assim, o objetivo desta pesquisa consistiu em verificar se a emissão de títulos de dívida, que envolvam covenants contratuais de rating, está associada com alterações nos valores das BTD. A amostra é composta pelas companhias abertas brasileiras listadas no Brasil, Bolsa e Balcão (B3) no período de 2000 a 2016. Os testes para dados em painel foram realizados com a variação da BTD e seus valores absolutos, considerando também o período pré e pós adoção das IFRS. Os achados demonstram que a emissão de debêntures com covenants contratuais de rating reduzem as variações e os valores absolutos das BTD, apenas para o período pré-IFRS. Isso sugere que as agências de rating podem entender grandes variações de BTD como sinal de risco e incerteza, e grandes valores de BTD como sendo decorrentes do gerenciamento de resultado e, assim, oferecer uma nota de rating mais baixa. Infere-se que os covenants de rating durante $\mathrm{O}$ período pré-IFRS podem ser considerados determinantes da BTD, porém, após essa adoção tal variável pode ter deixado de ser um determinante da BTD.

Palavras-Chave: Covenants contratuais. Rating. Book-tax differences.

\footnotetext{
1 Graduanda em Ciências Contábeis pela Universidade Federal de Uberlândia - UFU. Endereço: Av. João Naves de Ávila, n 2121, Bairro Santa Mônica, CEP 38.400-902, Uberlândia - MG. E-mail: alexia_ibrahim@hotmail.com. Telefone: (55) 34 3291-5904.

https://orcid.org/0000-0003-4874-6277

2 Doutora em Ciências Contábeis pela Universidade Federal de Uberlândia - UFU. Professora assistente do curso de Ciências Contábeis da Universidade Federal de Uberlândia - UFU. Endereço: R. Vinte, $n^{\circ} 1600$ - Bairro Tupã, CEP 38304-402, Ituiutaba - MG. E-mail: josilene@ufu.br. Telefone: (55) 34 3271-5260.

https://orcid.org/0000-0003-0545-1057.

3 Doutora em Controladoria e Contabilidade pela Universidade de São Paulo - USP. Professora da Faculdade de Ciências Contábeis (FACIC) da Universidade Federal de Uberlândia (UFU). Endereço: Av. João Naves de Ávila, n² 2121, sala 1F215, Bairro Santa Mônica, CEP 38.400-902, Uberlândia-MG. E-mail: patricia.costa@ufu.br. Telefone: (55) 34 3291-5904.

https://orcid.org/0000-0001-5087-1419.
} 


\title{
RATING-BASED COVENANTS: AN ASSOCIATION ANALYSES WITH BOOK-TAX DIFFERENCES
}

\begin{abstract}
Managers may be encouraged to solve issues that have a negative impact on ratings as they are relevant to a company's cost of debt and credit options. Because the book-tax differences (BTDs) may affect ratings, they may also be impacted by rating covenants, as managers may make decisions that result in BTDs that favor the credit rating. This study aims to assess if the issuance of debt securities involving rating covenants is associated with changes in BTDs. The sample consists of Brazilian publicly traded companies listed on B3 (Brasil, Bolsa and Balcão) from 2000 through 2016. The tests for panel data were carried out with variation of BTD and its absolute values, also considering the periods preceding and post IFRS adoption IFRS. The findings showed that the issuance of debentures with rating covenant reduced the absolute values of BTDs and their variations only for the pre-IFRS period. This suggests that by understanding 1) significant variations in the BTDs as indicative of risk and uncertainty and 2) high BTDs as derived from result management, rating agencies may provide lower rating scores. Rating covenants can be assumed to be determinant of BTD in the pre-IFRS period, but not thereafter.
\end{abstract}

Keywords: Covenants. Rating. Book-tax differences.

\section{INTRODUÇÃO}

A diferença entre o lucro contábil e o tributável (book-tax differences - BTD) tem origem principal na diferença entre normas contábeis e fiscais para apuração do lucro. Entretanto, uma parte das BTD pode ser decorrente do gerenciamento de resultados contábeis e/ou fiscais (Hanlon, 2005 Chan, Lin \& Mo, 2010 Martinez \& Passamani, 2014). Assim, as BTD podem ser um indicador adequado para detecção de gerenciamento de resultados (Hanlon, 2005 Blaylock, Shevlin \& Wilson, 2012 Cappellesso \& Rodrigues, 2019). Diante desse fato, Crabtree e Maher (2009) e Ayers, Laplante e MCGuire (2010) argumentam que valores extremos de BTD podem estar relacionados com o gerenciamento de resultados e, assim, pode reduzir a confiabilidade das informações financeiras e a persistência dos lucros e, por conseguinte, aumentar a chance de a empresa obter um rebaixamento no rating de crédito.

Crabtree e Maher (2009) e Ayers et al. (2010) investigaram os efeitos das BTD sobre os ratings, identificando que variações elevadas e valores extremos de BTD estão relacionados com rebaixamento de rating. Diante disso, é possível que os gestores, ao receberem um rebaixamento no rating, queiram solucionar as questões que contribuíram para que isso tivesse acontecido. Sendo assim, ao perceberem que as BTD podem impactar o rating, é provável que os gestores irão acompanhar os valores das BTD com mais cuidado e, talvez, ajustar de maneira discricionária as BTD como forma de receber um upgrade na avaliação de crédito.

A preocupação dos gestores em relação ao rating decorre do fato de esse indicador ser a opinião das agências de rating sobre a capacidade de um 
emissor de títulos de dívidas em honrar seus compromissos financeiros (Bouzouita \& Young, 1998), representando essa opinião uma medida de risco que afeta diretamente o preço dos títulos e ações e, em consequência, aumenta o custo da dívida, podendo, inclusive, facilitar ou dificultar a obtenção de recursos no mercado financeiro, impactando, portanto, a estrutura financeira da empresa (Gray, Mirkovic \& Ragunathan, 2006).

Especificamente, em casos em que há cláusulas de obrigações (covenants), segundo as quais a empresa deve manter um certo nível de rating, poderá haver mudança nas taxas ou recompra forçada se a empresa não conseguir manter o rating previsto no contrato (Kisgen, 2006). Assim, os gestores de empresas que emitiram títulos de dívida com cláusulas de rating (covenants) podem se preocupar com as oscilações e valores das BTD, visto que valores extremos de BTD podem representar gerenciamento de resultado e provocar a redução do rating.

Assim, o objetivo desta pesquisa é verificar se a emissão de títulos de dívida, que envolvam covenants contratuais de rating, está associada com alterações nos valores das BTD. Destaca-se que, nesta pesquisa, serão analisados apenas os covenants relacionados ao rating estabelecidos nos contratos de debêntures, segundo os quais a empresa deve manter, obrigatoriamente, um certo nível de rating, ou seja, o rating propriamente dito não é testado. A amostra da pesquisa é composta pelas companhias abertas brasileiras listadas no Brasil, Bolsa, Balcão (B3), no período de 2000 a 2016.

Apesar da relevância, poucos estudos têm explorado a relação entre BTD e rating (Crabtree \& Maher, 2009, Ayers et al., 2010). Além disso, a associação entre BTD e rating, nos casos em que há emissão de títulos de dívidas com cláusulas contratuais (covenants) relacionadas ao rating, permanece inexplorada na literatura. Assim, este estudo acrescenta às discussões acerca do tema uma análise sobre a associação das cláusulas contratuais de rating com as BTD. Mais especificamente, a análise tem o fim de verificar se as companhias abertas que emitiram título de dívidas com covenants de rating apresentam menores variações de BTD.

Em particular, este artigo traz novas visões para o tema, visto que examina explicitamente como essa relação acontece no Brasil cuja economia é emergente. Embora seja recorrente em nível mundial, o gerenciamento de resultados é particularmente preocupante em países emergentes, nos quais o nível de desenvolvimento dos mecanismos de governança necessários para lidar adequadamente com esse fenômeno pode não estar sendo satisfatório (Kaymak \& Bektas, 2015). Com base no argumento de que, nas economias emergentes, o nível de desenvolvimento institucional pode não ser suficiente para efetivamente atenuar a difusão e os impactos do gerenciamento, infere-se que, nesses países, os impactos positivos de gerenciamento de resultados tendem a ser mais fortes do que em suas contrapartes desenvolvidas. Assim, as BTD em países emergentes podem ter origem no gerenciamento de resultados numa proporção maior do que nos países desenvolvidos. Por conseguinte, a relação entre BTD, rating e covenants pode ser mais forte em países como o Brasil.

Além disso, a adoção das International Financial Reporting Standards (IFRS) no Brasil aumentou a diferença entre o lucro contábil e o tributável (Costa \& Lopes, 2015), o que pode favorecer o gerenciamento de resultados (Cappellesso 
\& Rodrigues, 2019). Dessa forma, conhecer os determinantes das BTD no Brasil, antes e após a adoção dessas normas, poderá ser útil para a avaliação da qualidade com que o lucro contábil e o tributável estão sendo apurados.

\section{REFERENCIAL TEÓRICO E HIPÓTESES}

O lucro financeiro e o tributável são apurados por meio de diferentes normas, resultando em valores distintos e, consequentemente, em diferenças entre os lucros contábil e tributável (book-tax differences - BTD). Embora essa seja a origem principal das BTD, destaca-se que uma parcela das mesmas pode também ser decorrente do gerenciamento de resultado financeiro e/ou tributável (Weber, 2009, Hanlon, 2005). Os gestores podem gerenciar o lucro contábil com o objetivo de aumentá-lo para atrair investidores e podem gerenciar o lucro tributável com o objetivo de pagar menos impostos. Além disso, os gestores podem suavizar o lucro contábil e o fiscal com o intuito de não atrair a atenção dos órgãos fiscais.

Nesse contexto, é possível observar estudos condizentes com as maiores BTD, em que se restringe o gerenciamento de resultados (Tang, 2014), e outros em que há um aumento na manipulação dos resultados (Burgstahler, Hail \& Leuz, 2006, Blaylock, Gaertner \& Shevlin, 2015). Os defensores de um menor nível de BTD asseveram que uma maior vinculação entre as normas financeiras e fiscais reduziria 0 nível de gerenciamento de resultados à medida que a discricionariedade dos gestores seria reduzida e os custos de seu oportunismo seriam elevados (Blaylock et al., 2015, Cappellesso \& Rodrigues, 2019). Desse modo, para esses autores, ao se reduzirem as BTD, os incentivos para o gerenciamento de resultados seriam restringidos, uma vez que o gerenciamento para elevar o resultado contábil seria seguido por maiores impostos, e o gerenciamento para reduzir o lucro tributável teria acompanhado um lucro contábil menor, o que desagradaria os investidores.

Por outro lado, alguns estudos mostram que a redução das BTD decorrente da conformidade entre normas societária e fiscal pode acarretar em um aumento do gerenciamento de resultados, pois um cenário no qual as normas fiscais e societária são harmônicas restringe a capacidade dos outsiders de identificar o gerenciamento devido à perda de informação (Tang, 2005, Blaylock et al., 2015, Cappellesso \& Rodrigues, 2019). Além disso, esses autores asseveram que a perda de informação gerada pelas menores BTD também pode levar à maior suavização de resultados devido às motivações tributárias). Assim, percebe-se que as BTD podem ser um indicador de gerenciamento de resultados, tanto contábil, quanto tributável.

Crabtree e Maher (2009) e Ayers et al. (2010) mostraram que as BTD têm conteúdo informacional que pode ser útil às agências de rating em suas avaliações. Crabtree e Maher (2009) demonstraram que valores de BTD distantes da média do setor resultam em rating desfavorável. Esses autores explicam que, quando a empresa apresenta lucro contábil bem maior que o lucro tributável, pode ser indício de gerenciamento de resultados. Nessa situação, o lucro pode estar artificialmente inflado, tornando as informações contábeis menos confiáveis e com a possibilidade de o lucro se tornar menor em períodos futuros. Em contraponto, o lucro tributável sendo bem maior que o lucro contábil pode 
indicar falha no planejamento tributário e altos pagamentos de impostos, cuja consequência pode ser refletida nos fluxos de caixa e crescimento da empresa (Crabtree \& Maher, 2009).

Ayers et al. (2010) provaram que grandes variações nas BTD também resultam em rating desfavorável. Isso significa que as agências de rating penalizam empresas com valores de BTD distantes da média do setor ou que apresentem grandes variações. A relação entre grandes variações nas BTD e rating pode ser explicada em virtude de que medidas de variação são reconhecidas como indicadores de risco e incerteza. Dessa forma, quanto maior a variação das BTD, maior o risco da empresa representado pelo rating (Ayers et al., 2010)

O rating se refere à opinião de uma determinada agência de rating sobre a capacidade da entidade em honrar seus compromissos financeiros. Trata-se de uma classificação feita por analistas especializados que revela o risco de crédito das empresas, o qual pode ser utilizado pelos investidores como um indicador em suas avaliações de risco de crédito e tomada de decisão (Soares, Coutinho \& Camargos, 2012). Assim, o papel das agências de rating no mercado financeiro se torna relevante, pois oferece suporte aos investidores nas questões de risco, insolvência e monitoramento das organizações (Adams, Burton \& Hardwick, 2003).

O monitoramento ocorre, pois, antes de realizar a avaliação, as agências de rating podem solicitar informações adicionais às empresas, além daquelas que são publicadas nos relatórios contábeis. Com isso, o rating permite, inclusive, reduzir a assimetria entre investidores e empresa (Murcia, 2013). Devido a esse fato, e por ser uma medida de risco, o rating impacta diretamente na precificação dos títulos e das ações e, em consequência, no custo de tais títulos, bem como na estrutura financeira da empresa, pois, dependendo da classificação, o rating pode favorecer ou dificultar a obtenção de recursos no mercado (Barron, Clare \& Thomas, 1997, Han, Shin, Reinhart \& Moore, 2009, Miiller \& Martinez, 2016).

Ao emitir títulos de dívidas em que há cláusulas contratuais (covenants relacionados ao rating), segundo as quais a empresa deve manter, obrigatoriamente, um certo nível de rating, poderá haver mudança nas taxas ou recompra forçada dos títulos caso a empresa não consiga manter o rating previsto no contrato (Kisgen, 2006). Assim, os gestores de empresas que emitiram títulos de dívida com cláusulas de rating (covenants) poderão se preocupar de maneira mais incisiva do que aquelas empresas que não emitiram esses títulos com as oscilações e valores das BTD, visto que grandes variações de BTD podem representar gerenciamento de resultado e provocar a redução do rating.

A hipótese dos covenants contratuais da perspectiva oportunística (Watts \& Zimmerman, 1990) prevê que os gestores poderão adotar procedimentos ex post ao estabelecimento de contratos como forma de alterar o lucro atual quando estão próximos de violar covenants contratuais (Watts \& Zimmerman, 1990). Segundo a definição de Borges (1999), covenants é "um compromisso ou promessa em qualquer contrato formal de dívida, reconhecido em lei, protegendo os interesses do credor e estabelecendo que determinados atos que não devem ou devem cumprir-se".

Devido à importância dos ratings para o custo da dívida e para a obtenção de recursos, os gestores podem ser motivados a solucionar questões que 
interferem negativamente no rating com o intuito de obter rating favorável. Nesse sentido, uma vez que as BTD podem impactar no rating, acredita-se que os covenants contratuais de rating também possam interferir nas BTD, pois os gestores poderão tomar decisões de forma a resultar em BTD que favoreçam a classificação de crédito.

Apesar da relevância, poucos estudos têm explorado a associação entre BTD e rating (Crabtree \& Maher, 2009, Ayers et al., 2010, Miiller \& Martinez, 2016, Barbosa, 2019). Além disso, a relação entre BTD e rating de crédito, nos casos em que há emissão de debêntures com cláusulas contratuais (covenants), permanece inexplorada na literatura. Assim, a primeira e segunda hipóteses do estudo são:

$\mathrm{H}_{1}$ : A emissão de debêntures com covenants contratuais de rating reduz os valores absolutos da BTD.

$\mathrm{H}_{2}$ : A emissão de debêntures com covenants contratuais de rating reduz as variações na BTD.

A adoção das International Financial Reporting Standards (IFRS) no Brasil aumentou as BTD (Costa \& Lopes, 2015), o que pode favorecer o gerenciamento de resultados. Koubaa e Anis (2015) explicam que as regras contábeis, principalmente aquelas baseadas em princípios, permitem flexibilidade por parte dos gestores quanto à escolha de critérios cuja finalidade é fornecer informações que representem melhor a situação econômico-financeira da empresa e que sejam úteis para os usuários no processo decisório. Muitas vezes, entretanto, os gestores acabam se utilizando dessa flexibilidade para mascarar o real desempenho da empresa, ou seja, gerenciam as informações não pensando em representar efetivamente o evento ocorrido (Koubaa \& Anis, 2015). Inclusive, na visão de Coelho e Lopes (2007), os gestores devem fazer uso das escolhas contábeis como forma de favorecer a captação de recursos.

Espera-se, portanto, que, principalmente, após a adoção das IFRS, os gestores se utilizem das ações discricionárias para manter as BTD em um patamar que seja favorável ao rating, por consequência, menores variações das BTD e valores absolutos das BTD estejam mais relacionadas com os covenants de rating do que no período pré-adoção. Assim, a terceira e quarta hipóteses de pesquisa são:

$\mathrm{H}_{3}$ : A emissão de debêntures com covenants contratuais de rating reduz os valores absolutos da BTD e essa associação tende a ser mais forte em períodos pós-adoção das IFRS do que em períodos pré-adoção.

$\mathrm{H}_{4}$ : A emissão de debêntures com covenants contratuais de rating reduz as variações da BTD e essa associação tende a ser mais forte em períodos pósadoção das IFRS do que em períodos pré-adoção.

Dessa forma, caso as hipóteses de pesquisa não sejam confirmadas há indícios de que os valores da BTD não sejam relevantes para impactar as notas de rating e, por conseguinte, não sejam relacionados aos covenants de rating. 


\section{PROCEDIMENTOS METODOLÓGICOS}

A presente pesquisa se classifica como exploratória, uma vez que se trata de um tema com pouco conhecimento. O período de análise dos dados corresponde ao espaço temporal de 2000 a 2016. A amostra é composta, inicialmente, por 304 companhias abertas brasileiras (5.168 observações). No entanto, as empresas do setor financeiro foram excluídas da amostra por apresentarem diferentes regras de tributação e registros contábeis, o que poderia enviesar o cálculo das BTD (Bis \& Martinez, 2017). Seguindo as recomendações de Hanlon (2005) e de Edwards, Schwab e Shevlin (2016), optou-se por não calcular as BTD nos anos em que houve prejuízo antes do cálculo dos tributos sobre o lucro, pois os prejuízos fiscais podem se tornar ativos fiscais diferidos, podendo, assim, enviesarem os efeitos das BTD na conta de despesa com imposto de renda diferido. A partir de tais critérios, a amostra final é composta por 1.255 observações de 236 empresas (Tabela 1).

\section{Tabela 1}

Amostra de pesquisa

\begin{tabular}{l|r}
\hline \multicolumn{1}{c|}{ Critérios de definição amostral } & Observações \\
\hline Amostra inicial & 5.168 \\
(-) Empresas do setor financeiro & $(595)$ \\
(-) LAIR negativo & $(1.105)$ \\
(-) Falta de dados para o cálculo & $(2.213)$ \\
da BTD & 1.255 \\
\hline Total &
\end{tabular}

Fonte: dados da pesquisa

O modelo utilizado para testar as hipóteses do estudo está especificado na Equação 1, o qual é testado com o valor absoluto das BTD e também com a variação da BTD, ambas no ano $t$ e ano $t+1$. Os testes com essa diferença temporal são realizados, pois acredita-se que cumprir com as cláusulas contratuais seja uma preocupação dos gestores a partir do momento em que os contratos são estabelecidos. Espera-se, portanto, que os covenants de rating sejam capazes de alterar os valores das BTD no ano $t$, ou seja, no mesmo ano em que o contrato da debênture é definido. Também, espera-se que isso aconteça no ano $t+1$, uma vez que os contratos de debêntures são de longo prazo (Pinto, Falcão \& Mól, 2015).

Além disso, três testes diferentes são realizados, considerando o período de análise: (a) período completo, que vai de 2000 a 2016, ou seja, 17 anos; (b) período que antecede a adoção das IFRS no Brasil, isto é, de 2000 a 2007 (pré IFRS); (c) período posterior à adoção das IFRS, que corresponde ao ano de 2010 até 2016 (pós IFRS). Os anos de 2008 e 2009 não incorporam o período pós adoção das IFRS, pois se referem ao período de transição da adoção de tais normas. A adição de período na análise poderia comprometer os resultados, uma vez que nesse período algumas empresas poderiam não ter adotado as normas em sua íntegra.

$B_{T D}=a+\beta_{1}$ Covrating $_{i t}+\beta_{2} A_{C C} D_{i t}+\beta_{3} R O A_{i t}+\beta_{4} O C_{i t}+\beta_{5} I M O B_{i t}+\beta_{6} T A M_{i t}+\beta_{7} L_{I} Q_{i t}+$ 
As BTDs foram calculadas de acordo com Wilson (2009), Comprix, Graham e Moore (2011) e Costa e Lopes (2015), conforme especificado na Equação 2.

$$
B D T_{i t}=\frac{L A I R_{i t}-L T_{i t}}{A T_{i t-1}}
$$

$B D T_{\text {it }}$ é a diferença total entre o lucro antes do cálculo do imposto de renda (LAIR) e o lucro tributável (LT) dividida pelo ativo total defasado (AT). O lucro tributável (LT) foi calculado pela divisão da despesa de imposto de renda corrente (IRC) pela alíquota máxima de imposto de renda para o Brasil que é de $34 \%$ (A), conforme sugerido por Hanlon (2005), Nakao (2012) e Costa e Lopes (2015). A variação das BTD é calculada pela diferença entre BTD ${ }_{i++}$ e $B T D_{i t}$.

A variável Covrating é uma dummy que recebe valor igual a 1 se a empresa emitiu debêntures com covenants contratuais de rating, e zero, caso contrário. Destaca-se que, nesta pesquisa, foram analisados apenas os títulos de dívidas em que há cláusulas contratuais de rating (covenants relacionados ao rating), segundo as quais a empresa deve manter obrigatoriamente um certo nível de rating.

As variáveis de controle estabelecidas na Equação 1 (ACD, ROA, OC, $I M O B$, TAM e LIQ) foram definidas com base nos resultados dos estudos de Manzon e Plesko (2002), Koubaa e Anis (2015) e Costa e Lopes (2015). A variável ACD it representa os accruals discricionários. A modalidade de gerenciamento de resultado testada neste estudo trata-se da target earnings. Xian, Sun e Zhang (2015) encontraram uma relação positiva entre BTD e accruals discricionários (ACD) calculados a partir do modelo de Jones, o qual foi modificado por Kothari, Leone e Wasley (2005), tendo sido essa medida também adotada neste estudo. O accruals total (ACT) para o modelo de Kothari Leone e Wasley (2005) é calculado com base na Equação 3.

$$
A C T_{i t}=\alpha 0+\alpha 1\left(1 / A T_{i t-1}\right)+\alpha 2 \Delta v e n d a s_{i t}+\alpha 3 I M O B_{i t}+\alpha 3 R O A_{i t}+\varepsilon_{i t}
$$

Em que: ACT é o accruals total; AT é o ativo total defasado; $\Delta$ vendas é a receita no período $t$ menos a receita do período $t-1$, escalonado pelo ativo total defasado; IMOB é o imobilizado do período t da empresa $i$ escalonado pelo ativo total defasado; e, ROA é o retorno do ativo (lucro operacional dividido pelo total de ativos) da empresa i no período $t$.

Os ACD são os resíduos da Equação 4 e podem assumir valores positivos ou negativos de modo que, quanto mais distante o resíduo estiver de zero, maior é o gerenciamento de resultado.

$$
A C T_{i t}=\Delta A C_{i t}-\Delta P C_{i t}-\Delta \operatorname{Cash}_{i t}+\Delta D P C_{i t}-D e p_{i t}
$$


Em que: ACT é o accruals total; $\triangle \mathrm{AC}$ é a variação no ativo circulante (ativo circulante ano $t$ menos ativo circulante ano $t-1) ; \triangle P C$ é a variação no passivo circulante (passivo circulante do ano $t$ menos passivo circulante do ano $t-1$ ); $\Delta$ Cash representa a variação no caixa e equivalentes de caixa (caixa e equivalentes de caixa do ano t menos caixa e equivalentes de caixa do ano $t-1$ ); $\triangle D P C$ é a variação da dívida incluída no passivo circulante; Dep representa a depreciação no ano $t$. Ressalta-se que todas as variáveis são escalonadas pelo ativo total defasado em $t-1$.

A rentabilidade pode ser um fator determinante das BTD, pois empresas com alta rentabilidade conseguem reduzir o pagamento de impostos por meio dos benefícios fiscais (Manzon \& Plesko, 2002, Koubaa \& Anis, 2015). Assim, foi utilizada a variável retorno sobre o ativo (ROA) como proxy de rentabilidade, tendo sido essa variável calculada pela divisão do lucro operacional pelo ativo total.

A variável OC representa a variação das vendas entre os anos $t$ e t- 1 escalonado pelo ativo total defasado. A oportunidade de crescimento (OC) pode apresentar uma relação positiva com as BTD, uma vez que, quanto maiores as receitas, mais as empresas tendem a gerenciar o resultado como forma de reduzir o pagamento de impostos (Manzon \& Plesko, 2002, Moore, 2012, Koubaa \& Anis, 2015).

Ativos do imobilizado, de acordo com os argumentos utilizados por Manzon e Plesko (2002) e Costa e Lopes (2015), possuem flexibilidade quanto às escolhas contábeis a respeito do método de depreciação, podendo os gestores utilizarem de forma discricionária essa flexibilidade para aumentar o lucro. Assim, IMOB representa o imobilizado no ano t dividido pelo AT defasado em t- 1;

O tamanho da empresa (TAM), medido pelo logaritmo natural do ativo total, foi acrescentado no modelo. No entanto, o sinal esperado da relação entre tamanho e BTD pode ser positivo ou negativo, sendo possível obter uma relação negativa ao considerar que empresas maiores tendem a cumprir melhor com as regras fiscais, evitando a evasão fiscal pois são mais fiscalizadas do que empresas menores (Chan, Lin \& Mo, 2010, Moore, 2012, Xian et al., 2015, Koubaa \& Anis, 2015). Por outro lado, também há evidências de que empresas maiores possuem também mais recursos disponíveis para fazer lobby em questões fiscais ou planejar as atividades com foco na redução de impostos e, assim, divulgar maiores BTD (Huang \& Chang, 2015), sendo possível, portanto, também encontrar relação positiva.

Evidências empíricas a respeito da associação das BTD com a liquidez é dúbia. Manzon e Plesko (2002), Koubaa e Anis (2015) e Fonseca e Costa (2017) mostram que o índice de liquidez (LIQ) pode ser uma variável importante na explicação das BTD, apresentando sinal positivo no coeficiente. Os argumentos para essa relação positiva são de que empresas com alta liquidez buscam reduzir o pagamento de impostos, gerando, assim, aumento nas BTD. Por outro lado, Costa e Lopes (2015) argumentam que empresas com baixa liquidez tendem a gerenciar o resultado como forma de mascarar a real situação financeira da empresa. Nesse caso, é possível também obter uma associação negativa entre BTD e liquidez, sendo o índice de liquidez corrente calculado pela relação entre ativo circulante e passivo circulante. 
A coleta dos dados financeiros foi realizada nas bases de dados Capital IQ e Thomson Reuters, em janeiro de 2018, e se referem às demonstrações consolidadas. Ressalta-se que, em se tratando de companhias com mais de um tipo de ação negociada em bolsa, foram selecionadas aquelas de maior liquidez. Já a informação sobre a emissão de títulos de dívida com covenants contratuais de rating foi obtida a partir da leitura das escrituras das debêntures, as quais estavam disponíveis durante o mês de janeiro de 2019 no site mantido pela Associação Brasileira das Entidades dos Mercados Financeiro e de Capitais.

Seguindo os estudos de Costa e Nakao (2017) e Blaylock, Gaertner e Shevlin (2017), com o objetivo de reduzir o efeito dos outilers nas inferências dos resultados, foi realizado o procedimento de winsorização das variáveis do modelo ao nível de 1\%. A estatística descritiva e a regressão linear múltipla foram estimadas e analisadas em estrutura de dados em painel. Os pressupostos de heterocedasticidade, normalidade e multicolinearidade do modelo foram testados, conforme dados apresentados na Tabela 2.

Tabela 2

Diagnósticos do modelo

\begin{tabular}{lccccc}
\hline \multirow{2}{*}{ Teste } & \multicolumn{2}{c}{ Normalidade } & Multicolinearidade & \multicolumn{2}{c}{ Heterocedasticidade } \\
\cline { 2 - 6 } & swilk & sfrancia & VIF & $\begin{array}{c}\text { Breusch- } \\
\text { Pagan }\end{array}$ & White \\
\cline { 2 - 6 } & Prob>z & Prob>z & Média VIF & Prob > chi2 & Prob > chi2 \\
\hline BTD no ano $t$ & 0,0000 & 0,0000 & 1,6300 & 0,0000 & 0,0000 \\
BTD no ano $t+1$ & 0,0000 & 0,0000 & 1,7100 & 0,0000 & 0,0000 \\
Variação da BTD no ano $t$ & 0,0000 & 0,0000 & 1,7300 & 0,0000 & 0,0000 \\
Variação da BTD no ano $t+1$ & 0,0000 & 0,0000 & 1,7200 & 0,4509 & 0,0001 \\
\hline
\end{tabular}

Fonte: dados da pesquisa

O teste de Breusch-Pagan mostra ausência de heterocedasticidade, ou seja, as variâncias dos erros são iguais e os resíduos são homoscedásticos. O teste Shapiro-Francia e o Shapiro-Wilk demonstram que os resíduos das regressões não apresentaram distribuição normal ao nível de significância de 5\%. Já a estatística de Variance Inflation Factor (VIF) apresenta valores abaixo de 3, o que sugere inexistência de multicolinearidade para todas as variáveis do modelo. Com o objetivo de minimizar os problemas decorrentes da homocedasticidade e não normalidade dos resíduos, os modelos foram estimados por erros padrões robustos.

A técnica utilizada para análise de dados é regressão múltipla, sendo que os modelos adotados no presente estudo foram estimados pelo método de Mínimos Quadrados Ordinários (MQO) com auxílio do Software Stata 13. Na Tabela 3, constam os resultados referente ao método de estimação adequado para cada modelo. Para o modelo com a BTD no ano t e BTD no ano $t+1$, o teste de Chow, Hausman e Breusch-Pagan apontam que os estimadores do efeito fixo e do modelo restrito não são consistentes e, portanto, o modelo é melhor estimado pelo método do efeito aleatório (Tabela 3). 
Tabela 3

Método de estimação

\begin{tabular}{|c|c|c|c|c|c|c|c|}
\hline \multirow{2}{*}{ Teste } & \multicolumn{2}{|c|}{ Chow } & \multicolumn{2}{|c|}{ Hausman } & \multicolumn{2}{|c|}{ Breusch-Pagan } & \multirow{2}{*}{$\begin{array}{l}\text { Método de } \\
\text { estimação } \\
\text { adequado }\end{array}$} \\
\hline & $F$ & $\begin{array}{c}\text { Prob } \\
>F\end{array}$ & Chi2 & $\begin{array}{c}\text { Prob> } \\
\text { chi2 }\end{array}$ & Chi2 & $\begin{array}{c}\text { Prob > } \\
\text { chibar2 }\end{array}$ & \\
\hline BTD no ano $t$ & 3,710 & 0,000 & 13,730 & 0,056 & 327,460 & 0,000 & Aleatório \\
\hline BTD no ano $t+1$ & 2,920 & 0,000 & 12 & 0,083 & 159,750 & 0,000 & Aleatório \\
\hline Variação da BTD no ano ${ }^{\dagger}$ & 0,810 & 0,963 & 22,890 & 0,002 & 0,000 & 1,000 & OLS \\
\hline Variação da BTD no ano $t+1$ & 0,620 & 0,999 & 7,310 & 0,397 & 0,000 & 1,000 & OLS \\
\hline
\end{tabular}

Fonte: dados da pesquisa

Para os modelos com a variação da BTD no ano t e variação da BTD no ano $t+1$ foram estimados pelo método OLS (Tabela 3).

\section{APRESENTAÇÃO DOS RESULTADOS}

A estatística descritiva é apresentada na Tabela 4. A média das BTD foi de 0,0321, semelhante aos resultados encontrados por Miiller e Martinez (2016), Marques, Nakao e Costa (2017) e Fonseca e Costa (2017).

Tabela 4

Estatística descritiva

\begin{tabular}{lrrrrrr}
\hline \multicolumn{1}{c}{ Variável } & $\begin{array}{c}\text { Número de } \\
\text { observações }\end{array}$ & \multicolumn{1}{c}{ Média } & $\begin{array}{l}\text { Desvio } \\
\text { padrão }\end{array}$ & Mínimo & Máximo & \multicolumn{1}{c}{ P50 } \\
\hline BTD & 1.255 & 0,0321 & 0,0445 & $-0,0306$ & 0,1442 & 0,0231 \\
VBTD & 863 & $-0,0032$ & 0,0371 & $-0,0812$ & 0,0775 & $-0,0026$ \\
ACD & 1.253 & 0,0178 & 0,0407 & $-0,0464$ & 0,1083 & 0,0132 \\
ROA & 1.254 & 0,0934 & 0,0573 & 0,0038 & 0,2178 & 0,0840 \\
OC & 1.254 & 0,0499 & 0,1858 & $-0,2442$ & 0,5118 & 0,0124 \\
IMOB & 1.254 & 0,2835 & 0,2539 & 0,0003 & 0,8191 & 0,2375 \\
TAM & 1.254 & 7,1691 & 1,3766 & 4,5716 & 9,4896 & 7,2584 \\
LIQ & 1.254 & 1,8050 & 0,9539 & 0,6475 & 4,3787 & 1,5442 \\
\hline
\end{tabular}

Nota: BTD - é a diferença total entre o lucro antes do cálculo do imposto de renda e o lucro tributável dividida pelo ativo total defasado; VBTD - é a variação da BTD calculada pela diferença entre $B T D_{i t+1}$ e $B T D_{i t ;}$ ACD - é o accruals discricionários calculado a partir do modelo de Jones modificado por Kothari, Leone e Wasley (2005); ROA - é o retorno sobre o ativo calculado pela divisão do lucro operacional pelo ativo total; OC - é a oportunidade de crescimento calculada pela variação das vendas entre os anos $t$ e $t-1$, escalonado pelo ativo total defasado; IMOB - é o imobilizado no ano t dividido pelo ativo total defasado em t-1; TAM - é o tamanho da empresa calculado pelo logaritmo natural do ativo total; $L I Q$ - é índice de liquidez corrente calculado pela relação entre ativo circulante e passivo circulante; P50 = mediana.

Fonte: dados da pesquisa

$\mathrm{Na}$ Tabela 5, são apresentadas as correlações de Spearman entre as variáveis de estudo. Percebe-se que as BTD e o accruals discricionários estão positivamente associados ao nível de $1 \%$ de significância, ocorrendo o mesmo com a variação das BTD. Isso significa que as empresas com maiores valores/variações de BTD também apresentam maior gerenciamento de resultado. Esse resultado reforça os achados de Ferreira, Martinez, Costa e Passamani. (2012), os quais documenta que as BTD têm associação positiva com 
os accruals discricionários, podendo, inclusive, serem utilizadas como uma medida de qualidade do lucro.

Destaca-se que a maioria das variáveis apresentaram associação significativa com as BTD e VBTD, exceto, tamanho e liquidez, os quais não foram significativos quanto à VBTD. Ressalta-se ainda que nenhum dos coeficientes ficou acima de 0,6 , indicando que as variáveis representam medidas distintas de risco padrão, ou seja, não apresenta forte correlação. Em suma, os resultados das correlações indicam que as variáveis do modelo estão adequadas para uma análise multivariada.

\section{Tabela 5}

Matriz de correlação de Spearman

\begin{tabular}{|c|c|c|c|c|c|c|c|c|}
\hline & BTD & VBTD & $A C D$ & $R O A$ & $O C$ & $I M O B$ & TAM & $L I Q$ \\
\hline \multirow[t]{2}{*}{ BTD } & 1 & & & & & & & \\
\hline & $\begin{array}{l}0,0000 \\
1,0000\end{array}$ & 10000 & & & & & & \\
\hline VBTD & 0,0000 & 0,0000 & & & & & & \\
\hline \multirow{2}{*}{$A C D$} & 0,4455 & 0,1249 & 1,0000 & & & & & \\
\hline & 0,0000 & 0,0002 & 0,0000 & & & & & \\
\hline \multirow{2}{*}{$R O A$} & 0,3118 & 0,1296 & 0,5127 & 1,0000 & & & & \\
\hline & 0,0000 & 0,0001 & 0,0000 & 0,0000 & & & & \\
\hline \multirow{2}{*}{$O C$} & 0,1443 & 0,1653 & $-0,1595$ & 0,1627 & 1,0000 & & & \\
\hline & 0,0000 & 0,0000 & 0,0000 & 0,0000 & 0,0000 & & & \\
\hline \multirow{2}{*}{$I M O B$} & $-0,1068$ & 0,0601 & $-0,5405$ & $-0,0142$ & 0,2113 & 1,0000 & & \\
\hline & 0,0002 & 0,0776 & 0,0000 & 0,6146 & 0,0000 & 0,0000 & & \\
\hline \multirow{2}{*}{ TAM } & $-0,0596$ & $-0,0136$ & $-0,2304$ & 0,0299 & 0,0435 & 0,0913 & 1,0000 & \\
\hline & 0,0349 & 0,6892 & 0,0000 & 0,2900 & 0,1237 & 0,0012 & 0,0000 & \\
\hline \multirow{2}{*}{ LIQ } & 0,1994 & $-0,0101$ & 0,2534 & $-0,0856$ & $-0,0424$ & $-0,1668$ & $-0,2672$ & 1,0000 \\
\hline & 0,0000 & 0,7680 & 0,0000 & 0,0024 & 0,1336 & 0,0000 & 0,0000 & 0,0000 \\
\hline
\end{tabular}

Nota: BTD - é a diferença total entre o lucro antes do imposto de renda e o lucro tributável dividida pelo ativo total defasado; VBTD - é a variação da BTD calculada pela diferença entre $B T D_{i++1}$ e BTD it; $A C D$ - é o accruals discricionários calculado a partir do modelo de Jones modificado por Kothari, Leone e Wasley (2005); ROA - é o retorno sobre o ativo calculado pela divisão do lucro operacional pelo ativo total; OC - é a oportunidade de crescimento calculada pela variação das vendas entre os anos $t$ e $t-l$, escalonado pelo ativo total defasado; IMOB - é o imobilizado no ano t dividido pelo ativo total defasado em t- 1 ; TAM - é o tamanho da empresa calculado pelo logaritmo natural do ativo total; LIQ - é índice de liquidez corrente calculado pela relação entre ativo circulante e passivo circulante.

Fonte: dados da pesquisa

Na Tabela 6, apresentam-se os resultados da regressão do modelo com as BTD em valores absolutos no ano $t$ e no ano $t+1$, tendo sido realizados três testes diferentes e considerando-se, primeiramente, o período completo, que vai de 2000 a 2016, ou seja, 17 anos. Além disso, foi realizado o teste pré IFRS, considerando o período que antecede a adoção das IFRS no Brasil, isto é, de 2000 a 2007, tendo sido realizado também o teste pós IFRS, que corresponde ao ano de 2010 até 2016 - período após-adoção das IFRS.

O coeficiente $(-0,0177)$ para BTD com a variável de interesse Covrating é significante apenas no período pré IFRS referente ao ano $\dagger$ (ao nível de 10\%). 0 sinal do coeficiente é negativo, conforme o esperado, o que indica que as empresas que emitem títulos de dívida com covenants de rating buscam reduzir os níveis de BTD. Isso acontece porque as agências de rating podem entender 
grandes valores de BTD como sendo decorrentes do gerenciamento de resultado e, assim oferecer uma nota de rating mais baixa (Crabtree \& Maher, 2009), no entanto não é significativo para os resultados da BTD e Covrating no ano t durante o período completo e pós IFRS.

Como se percebe, parece fazer sentido que o resultado seja significativo apenas no período pré IFRS, pois, no Brasil, antes da adoção das normas internacionais, havia uma maior conformidade entre lucro contábil e tributável. Nesse cenário, seria fácil interpretar grandes diferenças entre as duas medidas como sendo decorrentes das ações discricionárias dos gestores, tanto em relação ao lucro contábil para maior quanto ao lucro tributável para menos, ao passo que, no período pós IFRS, a própria adoção das normas internacionais tenha resultado em um maior distanciamento entre as duas medidas de lucro, conforme relatam Costa e Lopes (2015). Isso significa que, nesse cenário de pós IFRS, maiores valores de BTD não necessariamente significam gerenciamento de resultado, não sendo, portanto, um fator que impacte nas notas de ratings. Diante dos diferentes resultados para o período pré e pós IFRS, acredita-se que seja natural o resultado para o período completo não ser significativo, o que fortalece a ideia de que as IFRS, de fato, impactaram na relação entre as duas variáveis.

Os resultados das BTD no ano t sugerem que as cláusulas contratuais sejam de fato uma preocupação dos gestores a partir do momento em que os contratos são estabelecidos. Contudo, destaca-se que os resultados para o teste das BTD no ano $t+1$ não é significativo em nenhum dos períodos analisados (completo, pré e pós (FRS). Esse resultado pode indicar que, logo no primeiro ano em que os contratos de debêntures são estabelecidos, os gestores ajustam os valores das BTD para mantê-la em um patamar que seja favorável ao rating. Com isso, presume-me que, os gestores fazem esses ajustes logo no momento inicial da emissão das debêntures, fica garantida uma nota de rating favorável, pelo menos, até o final do ano seguinte.

A variável ACD tem coeficiente positivo, conforme o esperado, em todos os períodos analisados. O p-valor é de 0,0000 para todos os casos, sendo não significativo apenas no período pré IFRS com as BTD no ano $t+1$ com $p$-valor de 0,3080, sendo os coeficientes para BTD no ano t os seguintes: período completo $(0,7765)$; pré IFRS $(0,7265)$; pós IFRS $(0,8574)$. Já os coeficientes para BTD no ano $t+1$ são: período completo $(0,2083)$; pré IFRS $(0,1040)$; pós IFRS $(0,2455)$. Tais resultados apontam que os accruals discricionários são, de fato, uma medida importante para explicar as BTD, visto que, quanto maior o gerenciamento de resultado, maior aa BTD, sendo esse achado condizente com os resultados documentados por Frank et al. (2009), Koubaa e Anis (2015), Ferreira et al. (2012) e Xian et al. (2015).

Além disso, a variável ROA é significativa ao nível de 10\% (com p-valor $0,0590)$ para explicar as BTD no período pós IFRS testadas no ano $t$, porém o coeficiente negativo $(-0,0917)$ se contrapõe ao resultado esperado. Já no ano ++1 , o coeficiente foi positivo e significativo ao nível de $10 \%$ no período completo ( $p$-valor 0,0670 e coeficiente de 0,0642) e pós IFRS ( $p$-valor 0,0810 e coeficiente de 0,0741), confirmando os relatos na literatura de Chan et al. (2010), Moore (2012), Xian et al. (2015), Huang e Chang (2015) e Costa e Lopes (2015), segundo os quais empresas com alta rentabilidade conseguem reduzir o pagamento de impostos por meio dos benefícios fiscais. 
A oportunidade de crescimento (OC) tem o coeficiente positivo (o que era esperado) e significativo em todos os períodos analisados, exceto, no modelo com as BTD no ano $t+1$ pós IFRS. Os coeficientes e $p$-valor para BTD no ano $t$ são respectivamente: período completo $(0,0598 ; 0,0000)$; pré IFRS $(0,0491 ; 0,0010)$; pós IFRS $(0,0579 ; 0,0000)$. Já os coeficientes e $\mathrm{p}$-valor para BTD no ano $t+1$ são: período completo $(0,0133 ; 0,0520)$; pré IFRS $(0,0285 ; 0,0330)$; pós IFRS $(0,0004 ; 0,9610)$. Esse resultado corrobora os achados de Manzon e Plesko (2002) e Koubaa e Anis (2015), confirmando que empresas com altas receitas tendem a gerenciar o resultado como forma de reduzir o pagamento de impostos.

Por sua vez, o imobilizado é positivo e significativo apenas no período completo (coeficiente de 0,0441 e p-valor de 0,0000) e pós IFRS (coeficiente de 0,0627 e p-valor de 0,0000) para os testes com aa BTD no ano t. Tal evidência confirma que as empresas podem estar utilizando da flexibilidade de escolhas contábeis quanto ao método de depreciação dos ativos imobilizados para gerenciar o lucro em busca de evidenciar valores maiores, conforme apontam Manzon e Plesko (2002), Chan et al. (2010), Xian et al. (2015), Costa e Lopes (2015) e Fonseca e Costa (2017).

O tamanho da empresa também é positivo e significativo apenas no período completo (coeficiente de 0,0040 e p-valor de 0,0020) e pós IFRS (coeficiente de 0,0044 e p-valor de 0,0020) para os testes com as BTD no ano $t$. Embora a literatura apresenta resultados dúbios para essa variável, os achados da presente pesquisa são consoantes com os de Frank et al. (2009), Chan et al. (2010), Long, Ye e LV (2013), Huang e Chang (2015), Gomes (2016) e Fonseca e Costa (2017). Esses achados indicam que empresas maiores possuem também mais recursos disponíveis para fazer lobby em questões fiscais ou planejar as atividades com foco na redução de impostos e, assim, divulgar maiores BTD.

Já a liquidez corrente tem o sinal positivo e significativo em todos os períodos analisados, exceto, para o período pré IFRS. Os coeficientes e p-valor para BTD no ano † são, respectivamente: período completo $(0,0038 ; 0,0150)$; pré IFRS $(-0,0019 ; 0,5990)$; pós IFRS $(0,0045 ; 0,0080)$. Já os coeficientes e p-valor para BTD no ano $t+1$ são: período completo $(0,0031 ; 0,0720)$; pré IFRS $(0,0055 ; 0,3020)$; pós IFRS $(0,0034 ; 0,0530)$. Esse achado demonstra que empresas com alta liquidez buscam reduzir o pagamento de impostos, gerando, assim, aumento nas BTD. Tal achado corrobora com os relatos de Manzon e Plesko (2002), Koubaa e Anis (2015) e Fonseca e Costa (2017). 
Tabela 6

Regressão do modelo com a BTD em valores absolutos

\begin{tabular}{|c|c|c|c|c|c|c|c|c|}
\hline & & & & D no ano & & $B T D r$ & ano $t$ & \\
\hline Variáveis & Sinal & & $\begin{array}{l}\text { Período } \\
\text { completo }\end{array}$ & $\begin{array}{l}\text { Pré } \\
\text { IFRS }\end{array}$ & Pós IFRS & $\begin{array}{l}\text { Período } \\
\text { completo }\end{array}$ & $\begin{array}{l}\text { Pré } \\
\text { IFRS }\end{array}$ & $\begin{array}{l}\text { Pós } \\
\text { IFRS }\end{array}$ \\
\hline & & & EA & EA & EA & EA & EA & EA \\
\hline & & beta & 0,0013 & $-0,0177$ & 0,0056 & 0,0004 & 0,0026 & 0,0000 \\
\hline Covrating & - & estatística $t$ & 0,3600 & $-1,9100$ & 1,5900 & 0,1100 & 0,3700 & 0,0000 \\
\hline & & p-valor & 0,7220 & 0,0570 & 0,1120 & 0,9090 & 0,7100 & 0,9970 \\
\hline & & beta & 0,7765 & 0,7265 & 0,8574 & 0,2083 & 0,1040 & 0,2455 \\
\hline$A C D$ & + & estatística $t$ & 9,6500 & 4,3900 & 9,8100 & 3,8600 & 1,0200 & 3,7000 \\
\hline & & p-valor & 0,0000 & 0,0000 & 0,0000 & 0,0000 & 0,3080 & 0,0000 \\
\hline & & beta & $-0,0499$ & 0,0263 & $-0,0917$ & 0,0642 & 0,0004 & 0,0741 \\
\hline$R O A$ & + & estatística $t$ & $-1,0900$ & 0,2800 & $-1,8900$ & 1,8300 & 0,0100 & 1,7500 \\
\hline & & p-valor & 0,2770 & 0,7800 & 0,0590 & 0,0670 & 0,9950 & 0,0810 \\
\hline & & beta & 0,0598 & \begin{tabular}{|l|}
0,0491 \\
\end{tabular} & 0,0579 & 0,0133 & 0,0285 & 0,0004 \\
\hline$O C$ & + & estatística ${ }_{t}$ & 9,2600 & 3,4700 & 6,9900 & 1,9400 & 2,1300 & 0,0500 \\
\hline & & p-valor & 0,0000 & 0,0010 & 0,0000 & 0,0520 & 0,0330 & 0,9610 \\
\hline & & beta & 0,0441 & 0,0361 & 0,0627 & 0,0068 & 0,0008 & 0,0085 \\
\hline IMOB & + & estatística t & 5,1900 & 1,6400 & 6,4700 & 0,9600 & 0,0400 & 1,0700 \\
\hline & & p-valor & 0,0000 & 0,1010 & 0,0000 & 0,3350 & 0,9720 & 0,2830 \\
\hline & & beta & 0,0040 & 0,0004 & 0,0044 & $-0,0001$ & 0,0003 & 0,0006 \\
\hline TAM & $-\mathrm{OU}+$ & estatística + & 3,0700 & 0,1100 & 3,1500 & $-0,0500$ & 0,0700 & 0,5200 \\
\hline & & p-valor & 0,0020 & 0,9100 & 0,0020 & 0,9570 & 0,9430 & 0,6020 \\
\hline & & beta & 0,0038 & $-0,0019$ & 0,0045 & 0,0031 & 0,0055 & 0,0034 \\
\hline LIQ & + & estatística $t$ & 2,4200 & $-0,5300$ & 2,6300 & 1,8000 & 1,0300 & 1,9400 \\
\hline & & p-valor & 0,0150 & 0,5990 & 0,0080 & 0,0720 & 0,3020 & 0,0530 \\
\hline & & beta & $-0,0273$ & $-0,0046$ & $-0,0331$ & 0,0160 & 0,0150 & 0,0090 \\
\hline Constante & $?$ & estatística $t$ & $-2,5600$ & $-0,1800$ & $-2,7100$ & 1,5000 & 0,4900 & 0,8500 \\
\hline & & p-valor & 0,0100 & 0,8540 & 0,0070 & 0,1330 & 0,6270 & 0,3940 \\
\hline R-square whi & hin & & 0,3468 & 0,3518 & 0,3685 & 0,0525 & 0,0099 & 0,0688 \\
\hline R-square bet & ween & & 0,3098 & 0,2042 & 0,3500 & 0,1525 & 0,1515 & 0,1658 \\
\hline R-square ove & & & 0,3487 & 0,2586 & 0,3836 & 0,1403 & 0,0882 & 0,1911 \\
\hline Prob > F & & & 0,0000 & 0,0000 & 0,0000 & 0,0000 & 0,1140 & 0,0000 \\
\hline Número obse & xções & & 1253 & 228 & 932 & 1127 & 204 & 825 \\
\hline Número de o & rupos & & 237 & 87 & 231 & 232 & 69 & 221 \\
\hline
\end{tabular}

Nota: Covrating - é uma dummy que recebe valor igual a 1 se a empresa emitiu debêntures com covenants contratuais de rating, e zero caso contrário; BTD - é a diferença total entre o lucro antes do imposto de renda e o lucro tributável dividida pelo ativo total defasado; $A C D$ - é o accruals discricionários calculado a partir do modelo de Jones modificado por Kothari, Leone e Wasley (2005); ROA - é o retorno sobre o ativo calculado pela divisão do lucro operacional pelo ativo total; $O C$ - é a oportunidade de crescimento calculada pela variação das vendas entre os anos $t$ e $t-1$, escalonado pelo ativo total defasado; IMOB - é o imobilizado no ano $t$ dividido pelo ativo total defasado em $t$ - 1 ; TAM - é o tamanho da empresa calculado pelo logaritmo natural do ativo total; $L I Q$ - é índice de liquidez corrente calculado pela relação entre ativo circulante e passivo circulante.

Fonte: dados da pesquisa

Na Tabela 7, constam os resultados para $\triangle B T D$. Semelhante ao resultado com a BTD em valores absolutos, o coeficiente $(-0,0225)$ é significativo $(0,0370)$ ao nível de $5 \%$ apenas no período pré IFRS com a $\triangle B T D_{\text {t. }}$ Esse achado demonstra que a emissão de debêntures com covenants contratuais de rating reduzem as variações da BTD, confirmando os argumentos de Ayers et al. (2010) de que grandes variações de BTD indicam maior risco e, portanto, são vistas de forma negativa pelas agências de rating. Assim, para evitar um rebaixamento no rating, 
e/ou para manter o rating no nível determinado pelas cláusulas contratuais, os gestores se motivam a interferir nos valores da BTD.

Tabela 7

Regressão do modelo com a variação da BTD

\begin{tabular}{|c|c|c|c|c|c|c|c|c|}
\hline 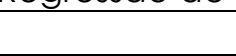 & & & & $D$ no ano & & VBTL & no ano $t$ & +1 \\
\hline $\begin{array}{l}\text { Variáveis } \\
\text { explicativas }\end{array}$ & $\begin{array}{l}\text { Sinal } \\
\text { previst }\end{array}$ & & $\begin{array}{l}\text { Período } \\
\text { completo }\end{array}$ & Pré IFRS & $\begin{array}{l}\text { Pós } \\
\text { IFRS }\end{array}$ & $\begin{array}{c}\text { Período } \\
\text { complet } \\
0\end{array}$ & Pré IFRS & $\begin{array}{l}\text { Pós } \\
\text { IFRS }\end{array}$ \\
\hline & & & OLS & OLS & OLS & OLS & OLS & OLS \\
\hline & & Beta & $-0,0020$ & $-0,0225$ & 0,0012 & $-0,0079$ & $-0,0195$ & $-0,0035$ \\
\hline Covrating & - & estatística $\dagger$ & $-0,5200$ & $-2,1000$ & 0,2900 & $-1,8100$ & $-1,5100$ & $-0,7500$ \\
\hline & & p-valor & 0,6030 & 0,0370 & 0,7700 & 0,0710 & 0,1330 & 0,4530 \\
\hline & & Beta & 0,2811 & 0,2542 & 0,2849 & 0,0558 & $-0,2430$ & 0,1670 \\
\hline$A C D$ & + & estatística $t$ & 3,9500 & 1,5600 & 3,3600 & 0,8200 & $-1,9500$ & 2,0500 \\
\hline & & p-valor & 0,0000 & 0,1200 & 0,0010 & 0,4110 & 0,0530 & 0,0400 \\
\hline & & Beta & $-0,0510$ & 0,0495 & $-0,0778$ & 0,0178 & 0,1130 & $-0,0287$ \\
\hline$R O A$ & + & estatística $t$ & $-1,3000$ & 0,5500 & $-1,6100$ & 0,5400 & 1,4500 & $-0,6000$ \\
\hline & & p-valor & 0,1960 & 0,5820 & 0,1080 & 0,5890 & 0,1500 & 0,5480 \\
\hline & & Beta & 0,0424 & 0,0350 & 0,0363 & 0,0017 & 0,0074 & $-0,0089$ \\
\hline OC & + & estatística $t$ & 4,9300 & 1,7500 & 3,2700 & 0,2300 & 0,4000 & $-0,9100$ \\
\hline & & p-valor & 0,0000 & 0,0830 & 0,0010 & 0,8170 & 0,6930 & 0,3630 \\
\hline & & Beta & 0,0245 & 0,0226 & 0,0319 & 0,0047 & $-0,0151$ & 0,0145 \\
\hline$I M O B$ & + & estatística & 3,5100 & 1,1800 & 3,8700 & 0,6700 & $-0,8500$ & 1,7100 \\
\hline & & p-valor & 0,0000 & 0,2400 & 0,0000 & 0,5060 & 0,3960 & 0,0870 \\
\hline & & Beta & 0,0012 & $-0,0037$ & 0,0015 & 0,0005 & $-0,0032$ & 0,0011 \\
\hline TAM & - OU + & estatística $t$ & 1,2000 & $-1,1800$ & 1,3700 & 0,4300 & $-0,9600$ & 0,9100 \\
\hline & & p-valor & 0,2300 & 0,2410 & 0,1720 & 0,6650 & 0,3370 & 0,3640 \\
\hline & & Beta & $-0,0003$ & $-0,0080$ & 0,0002 & $-0,0031$ & $-0,0017$ & $-0,0047$ \\
\hline$L I Q$ & + & estatística $t$ & $-0,1700$ & $-1,5200$ & 0,1300 & $-1,6800$ & $-0,3800$ & $-2,3500$ \\
\hline & & p-valor & 0,8670 & 0,1320 & 0,8970 & 0,0940 & 0,7080 & 0,0190 \\
\hline & & Beta & $-0,0199$ & 0,0178 & $-0,0232$ & $-0,0069$ & 0,0183 & $-0,0101$ \\
\hline Constante & $?$ & estatística $t$ & $-2,1600$ & 0,6700 & $-2,2300$ & $-0,6800$ & 0,6600 & $-0,9400$ \\
\hline & & p-valor & 0,0310 & 0,5060 & 0,0260 & 0,4970 & 0,5100 & 0,3480 \\
\hline $\begin{array}{l}\text { R-square whit } \\
\text { R-square betv } \\
\text { R-square over }\end{array}$ & en & & 0,0711 & 0,1135 & 0,0562 & 0,0151 & 0,0673 & 0,0279 \\
\hline Prob > F & & & 0,0000 & 0,0414 & 0,0003 & 0,2293 & 0,1740 & 0,0348 \\
\hline $\begin{array}{l}\text { Número obse } \\
\text { Número de gi }\end{array}$ & $\begin{array}{l}\text { ações } \\
\text { oos }\end{array}$ & & 863 & 127 & 676 & 757 & 125 & 585 \\
\hline
\end{tabular}

Nota: Covrating - é uma dummy que recebe valor igual a 1 se a empresa emitiu debêntures com covenants contratuais de rating, e zero, caso contrário; VBTD - é a variação da BTD calculada pela diferença entre BTD ittl $_{\text {e }}$ BTD it; $A C D$ - é o accruals discricionário calculado a partir do modelo de Jones modificado por Kothari, Leone e Wasley (2005); ROA - é o retorno sobre o ativo calculado pela divisão do lucro operacional pelo ativo total; OC - é a oportunidade de crescimento calculada pela variação das vendas entre os anos $t$ e $t-l$, escalonado pelo ativo total defasado; IMOB - é o imobilizado no ano $t$ dividido pelo ativo total defasado em t-1; TAM - é o tamanho da empresa calculado pelo logaritmo natural do ativo total; $L I Q$ - é índice de liquidez corrente calculado pela relação entre ativo circulante e passivo circulante.

Fonte: dados da pesquisa

A explicação para o fato de o resultado não ser significativo no período completo e pós IFRS é semelhante àquela dada quando dos resultados com os valores absolutos da BTD. Isso significa que a maior conformidade entre normas 
contábeis e tributáveis no Brasil, antes da adoção das IFRS, limitava os gestores quanto à flexibilidade nas escolhas contábeis, diferentemente do que ocorre após a adoção das IFRS. Para Koubaa e Anis (2015), as regras contábeis baseadas em princípios proporcionam maior flexibilidade aos gestores, permitindo diferentes escolhas de critérios. Assim, no período pré IFRS, quaisquer variações nas BTD poderiam ser vistas pelas agências de rating como um sinal de manipulação dos resultados. Em contraponto, após a adoção das IFRS, pode ser um pouco natural que as BTD tenham uma variação maior.

Por outro lado, quando a $\triangle B T D$ é testada no ano $t+1$, o resultado é significativo $(0,0710)$ apenas no período completo, cujo coeficiente é $-0,0079$. Esse resultado confirma a predição de que, mesmo com o fato de as debêntures serem títulos de longo prazo, os gestores continuam a se preocupar com os valores que podem interferir no rating, nesse caso específico, as BTD, em períodos posteriores à emissão dos contratos com covenants de rating.

A variável ACD tem o coeficiente positivo (como esperado) e significativo ao nível de $1 \%$ no período completo (coeficiente de 0,281 1 e p-valor de 0,0000) e pós IFRS (coeficiente de 0,2849 e p-valor de 0,0010) com a $\triangle B T D$ no ano $t$, sendo significativo ao nível de $10 \%$ no período pré IFRS (coeficiente de -0,2430 e p-valor de 0,0530 ) e ao nível de $5 \%$, no período pós IFRS (coeficiente de 0,1670 e p-valor de 0,0400 ) com a $\triangle B T D_{t+1}$, o que indica que, quanto maior o gerenciamento de resultado, maior a $\triangle B T D$. No entanto, no período pré IFRS, o sinal do ACD foi negativo com a $\triangle B T D_{t+1}$, demonstrando que, nesse período especifico, quanto maior o gerenciamento de resultado, menor é a $\triangle B T D_{t+1}$. Esse achado sugere que, antes da adoção das IFRS, as empresas podem ter gerenciado o resultado com o objetivo de reduzir as variações nas BTD, uma vez que grandes variações nas BTD podem ser vistas pelo mercado como um sinal de risco (Ayers et al., 2010).

Diferentemente dos resultados encontrados com as BTD em valores absolutos, a variável ROA não é significativa para explicar a $\triangle B T D$ em qualquer dos períodos testados, o que significa que o ROA não parece ser uma medida interessante para explicar as variações na BTD.

Por sua vez, a oportunidade de crescimento (OC) tem o coeficiente positivo (o que era esperado) e significativo em todos os períodos analisados com a $\triangle B T D_{\text {t, }}$ sendo seus coeficientes e $\mathrm{p}$-valor, respectivamente: período completo $(0,0424 ; 0,0000)$; pré IFRS $(0,0350 ; 0,0830)$; pós IFRS $(0,0363 ; 0,0010)$. Esse resultado, mais uma vez, sugere que empresas com altas receitas tendem a gerenciar o resultado como forma de reduzir o pagamento de impostos (Manzon \& Plesko, 2002, Koubaa \& Anis, 2015). No entanto, os achados não são significativos para os testes da $\triangle B T D_{t+1}$.

O coeficiente da variável IMOB é positivo e significativo ao nível de $1 \%$ no período completo (coeficiente de 0,0245 e p-valor de 0,0000) e pós IFRS (coeficiente de 0,0319 e p-valor de 0,0000) para os testes com a $\triangle B T D_{\text {t, }}$ mas é significativo ao nível de $10 \%$ no período pós IFRS (coeficiente de 0,0145 e p-valor de 0,0870 ) com a $\triangle B T D_{t+1}$. Assim, constata-se novamente que a flexibilidade de escolhas contábeis quanto ao método de depreciação dos ativos imobilizados deve ser utilizada pelos gestores como forma de aumentar os valores dos lucros discricionariamente, como asseveram Manzon e Plesko (2002), Chan et al. (2010), Xian et al. (2015), Costa e Lopes (2015) e Fonseca e Costa (2017). 
Ao contrário do resultado encontrado com as BTD em valores absolutos, o tamanho da empresa não é significativo para explicar a $\triangle B T D$ em quaisquer dos períodos analisados. Isso significa que o tamanho da empresa não se relaciona com a variação das BTD, da mesma forma que com os valores absolutos das BTD. É oportuno lembrar que os achados de Frank et al. (2009), Chan et al. (2010), Long, Ye e LV (2013), Huang e Chang (2015), Gomes (2016) e Fonseca e Costa (2017) sugerem que empresas maiores possuem também mais recursos para planejar suas atividades com vistas à redução de impostos e, assim, divulgar maiores BTD. Além disso, é possível considerar que o fato de a empresa divulgar maiores BTD não necessariamente significa que as BTD em si terão uma maior variação, pois pode ser que as empresas já mantenham as BTD em um nível alto.

A liquidez corrente tem o sinal negativo e significativo apenas com a $\triangle B T D_{t+1}$ para o período completo (coeficiente de -0,0031 e p-valor de 0,0940) e pós IFRS (coeficiente de -0,0047 e p-valor de 0,0190). Tais evidências demonstram que, quanto menor a liquidez corrente, maior é a $\triangle B T D_{t+1}$. Isso sugere que faz sentido os argumentos de Costa e Lopes (2015) de que empresas com baixa liquidez tendem a gerenciar o resultado como forma de mascarar a real situação financeira da empresa, ou seja, o gerenciamento poderia gerar uma maior variação nas BTD.

Testes adicionais foram realizados, considerando as BTD positivas (BTDPO) e negativas (BTDNE) em valores absolutos. Também foram realizados testes com as variações positivas ( $\triangle P O B T D$ ) e negativas das BTD ( $\triangle N E B T D$ ).

Os achados para BTDPO são significativos, ao nível de $10 \%$, e negativos no período pré IFRS (coeficiente de -0.0086 e p-valor de 0.078) no ano $t$, bem como em $t+1$ (com coeficiente de -0.0113 e p-valor de 0.063). Isso demonstra que, quando as empresas emitem títulos de dívida com covenants de rating, elas tendem a relatar menores valores de BTD positivas. Esse resultado era esperado, uma vez que grandes valores de BTD podem sugerir gerenciamento de resultado, o que pode ser visto como um sinal negativo pelas agências de rating no momento das avaliações (Crabtree \& Maher, 2009).

Já para BTDPO no ano $t$ e no período pós IFRS, o sinal do coeficiente é positivo (0.006) e significativo ao nível de 10\% (0.074), indicando que a tendência, nesse período especifico, é que as empresas divulguem BTDPO com valores mais elevados quando possuem covenants de ratings nos contratos de dívidas. Embora seja o contrário do esperado, esse resultado faz algum sentido, pois a adoção das IFRS no Brasil aumentou os níveis de BTD (Costa \& Lopes, 2015), podendo a desvinculação entre normas contábil e tributável sugerir uma melhora na qualidade das informações divulgadas pelos gestores (Nakao, 2012). Em adição, os estudos de Bushman e Smith (2001) e Barth et al. (2012) mostram que a adoção das normas internacionais de contabilidade melhora a qualidade da informação contábil. Além disso, BTDPO significa que o lucro contábil é maior que o lucro tributável, o que pode sugerir que as empresas estão realizando um bom planejamento tributário, pagando menos impostos, podendo favorecer o caixa e, assim, serem vistas de forma positiva pelas agências de rating (Crabtree \& Maher, 2009). Portanto, faz sentido que as empresas com covenants de rating divulguem $B T D P O_{t+1}$ com níveis mais altos, pois seria um sinônimo de qualidade da informação, o que pode ser visto pelas agências de rating como algo positivo e, em consequência, favorecer as notas de rating. 
Os resultados para BTDNE são significativos ao nível de $10 \%$ apenas no ano t+ 1 no período completo (coeficiente de 0.0047 e p-valor de 0.092) e pré IFRS (coeficiente de -0.0097 e p-valor de 0.080 ), sendo o sinal do coeficiente positivo, ou seja, o contrário do esperado. Essa relação positiva parece não fazer sentido, uma vez que BTDNE significa que o lucro contábil é menor que o lucro tributável, podendo essa situação indicar que as empresas não estão com planejamento tributário adequado e, em consequência, estariam pagando mais impostos do que deveriam. A falta de planejamento tributário pode impactar negativamente o caixa da empresa e, consequentemente, ser um sinal de risco e alerta, fazendo com que a nota de rating receba um dowgrade (Crabtree \& Maher, 2009).

Em relação à $\triangle P O B T D$, os achados apontam para o sinal esperado (-0.0360) e significativo ao nível de $1 \%(0.003)$ apenas no período pré IFRS no ano $t$. Isso significa que a emissão de títulos de dívida com covenants contratuais de rating reduzem as variações positivas das BTD. Essa evidência era esperada, pois grandes variações positivas nas BTD sinalizam informações negativas (redução da qualidade dos lucros) para os analistas de crédito (Ayers et al. 2010). Já os resultados para $\triangle$ NEBTD não são significantes.

Na Tabela 8, é apresentado um resumo dos resultados no que se refere à relação entre BTD e covenants contratuais de rating.

\section{Tabela 8}

Resumo dos resultados

\begin{tabular}{|c|c|c|c|c|c|c|c|}
\hline & & \multicolumn{2}{|c|}{ Período completo } & \multicolumn{2}{|c|}{ Pré IFRS } & \multicolumn{2}{|c|}{ Pós IFRS } \\
\hline & & $\begin{array}{c}\text { Result } \\
\text { ado }\end{array}$ & $\begin{array}{c}\text { Confirma } \\
\text { qual } \\
\text { hipótese? }\end{array}$ & Resultado & $\begin{array}{c}\text { Confirma } \\
\text { qual } \\
\text { hipótese? }\end{array}$ & Resultado & $\begin{array}{c}\text { Confirma } \\
\text { qual } \\
\text { hipótese? }\end{array}$ \\
\hline \multirow{2}{*}{$\begin{array}{l}\text { BTD em } \\
\text { valores } \\
\text { absolutos }\end{array}$} & BTD no ano $t$ & NSIG & Nenhuma & - & $\mathrm{H}_{1}$ & NSIG & Nenhuma \\
\hline & BTD no ano $t+1$ & NSIG & Nenhuma & NSIG & Nenhuma & NSIG & Nenhuma \\
\hline \multirow{2}{*}{$\begin{array}{l}\text { Variação da } \\
\text { BTD }\end{array}$} & BTD no ano $t$ & NSIG & Nenhuma & - & $\mathrm{H}_{2}$ & NSIG & Nenhuma \\
\hline & BTD no ano $t+1$ & - & $\mathrm{H}_{2}$ & NSIG & Nenhuma & NSIG & Nenhuma \\
\hline \multirow{2}{*}{$\begin{array}{l}\text { BTD positiva } \\
\text { em valores } \\
\text { absolutos } \\
\end{array}$} & BTD no ano $t$ & NSIG & Nenhuma & - & $\mathrm{H}_{1}$ & + & Nenhuma \\
\hline & BTD no ano $t+1$ & NSIG & Nenhuma & - & $\mathrm{H}_{1}$ & NSIG & Nenhuma \\
\hline \multirow{2}{*}{$\begin{array}{l}\text { Variação da } \\
\text { BTD positiva }\end{array}$} & BTD no ano $t$ & NSIG & Nenhuma & - & $\mathrm{H}_{2}$ & NSIG & Nenhuma \\
\hline & BTD no ano $t+1$ & NSIG & Nenhuma & NSIG & Nenhuma & NSIG & Nenhuma \\
\hline \multirow{2}{*}{$\begin{array}{l}\text { BTD } \\
\text { negativa em } \\
\text { valores } \\
\text { absolutos }\end{array}$} & BTD no ano $t$ & NSIG & Nenhuma & NSIG & Nenhuma & NSIG & Nenhuma \\
\hline & BTD no ano $t+1$ & + & Nenhuma & + & Nenhuma & NSIG & Nenhuma \\
\hline \multirow{2}{*}{$\begin{array}{l}\text { Variação da } \\
\text { BTD } \\
\text { negativa }\end{array}$} & BTD no ano $t$ & NSIG & Nenhuma & NSIG & Nenhuma & NSIG & Nenhuma \\
\hline & BTD no ano $t+1$ & NSIG & Nenhuma & NSIG & Nenhuma & NSIG & Nenhuma \\
\hline
\end{tabular}

Nota: NSIG é não significativo.

Fonte: dados da pesquisa.

Em suma, os resultados da relação entre covenants contratuais de rating e BTD sugerem que a emissão de títulos de dívida com covenants contratuais de rating reduzem as variações das BTD no ano $\dagger$ e $t+1$, o que permite confirmar a hipótese 2 de pesquisa. Isso sugere que grandes variações de BTD indicam maior risco e, por isso, são vistas de forma negativa pelas agências de rating. Por esse 
motivo, os gestores buscam cumprir com as cláusulas contratuais e isso parece acontecer tanto no ano $t$ quanto em $t+1$, o que justifica, uma vez que os contratos de debêntures são de longo prazo.

Os achados também indicam que, quando emitem títulos de dívida com covenants de rating, as empresas buscam reduzir os níveis de BTD, o que permite confirmar a hipótese 1 de pesquisa. Isso sugere que o rating pode incentivar os gestores a se utilizarem das ações discricionárias para manter as BTD em um patamar que seja favorável às classificações de rating. Por outro lado, não é possível confirmar as hipóteses 3 e 4 de que "a emissão de títulos de dívida com covenants contratuais de rating reduzem os valores absolutos e as variações das BTD, com uma tendência a serem mais fortes em períodos pós-adoção das IFRS do que em períodos pré-adoção". Isso porque os resultados não são significativos em quaisquer dos testes que envolvem o período pós IFRS, exceto, BTDPO + cujo sinal foi positivo, ou seja, contrário do esperado.

\section{CONSIDERAÇÕES FINAIS}

O objetivo desta pesquisa consistiu em verificar se a emissão de títulos de dívida, que envolvam covenants contratuais de rating, está associada com alterações nos valores das BTD. A amostra da pesquisa foi delimitada e abarcou as companhias abertas brasileiras listadas no Brasil, Bolsa, Balcão (B3), no período de 2000 a 2016. Os testes foram feitos, considerando-se esse período total, porém também foram feitos testes, considerando-se o período pré e pós IFRS.

Os principais resultados sugerem que a emissão de títulos de dívida com covenants contratuais de rating reduzem as variações das BTD, sugerindo que grandes variações de BTD indicam maior risco e, por isso, são vistas de forma negativa pelas agências de rating. No mesmo sentido, as evidências também indicam que, quando emitem títulos de dívida com covenants de rating, as empresas buscam reduzir os níveis de BTD. A explicação para essa associação é que as agências de rating podem entender grandes valores de BTD como sendo decorrentes do gerenciamento de resultado e, assim, oferecer uma nota de rating mais baixa. Nesse sentido, os achados demonstram que o rating ou as questões relacionadas ao rating podem incentivar os gestores a se utilizarem das ações discricionárias para manter as BTD em um patamar que seja favorável às classificações de rating. Assim, as hipóteses de que a emissão de títulos de dívida com covenants contratuais de rating reduzem os valores absolutos e as variações das BTD são confirmadas apenas para o período pré-IFRS.

Uma vez que os resultados não são significativos em quaisquer dos testes que envolvem o período pós IFRS, exceto, BTDPO + cujo sinal foi positivo, ou seja, contrário do esperado, não é possível confirmar as hipóteses de que a emissão de títulos de dívida com covenants contratuais de rating reduzem os valores absolutos e as variações das BTD, com uma tendência a serem mais fortes em períodos pós-adoção das IFRS do que em períodos pré-adoção. Assim, não se pode afirmar que, principalmente, após a adoção das IFRS, os gestores se utilizem das ações discricionárias para manter as BTD em um patamar que seja favorável ao rating. O que parece é que isso ocorre, principalmente, no período préadoção das IFRS, podendo ser explicado devido ao fato de que, nesse período, havia uma maior conformidade entre normas contábeis e tributáveis no Brasil. Isso 
significa que, se as empresas divulgam grandes diferenças entre as duas medidas nesse período, elas chamariam a atenção do governo e de usuários externos para a suspeita de que tais diferenças seriam em decorrência das ações discricionárias dos gestores, diferentemente do que ocorreu no período pós IFRS, já que tais normas internacionais resultaram, de forma natural, em maior distanciamento entre as duas medidas de lucro (Costa \& Lopes 2015).

Como conclusões de pesquisa, têm-se que: a) os gestores podem ter incentivos para solucionar as questões que podem interferir de forma negativa no rating, especificamente, em busca de manter o rating em um patamar favorável frente ao cumprimento de contratos que envolvem covenants de rating; e b) separar o período entre pré adoção e pós adoção das IFRS é relevante para compreensão da associação entre BTD e as cláusulas de rating; c) os covenants de rating durante $O$ período pré-IFRS podem ser considerados como determinantes da BTD, porém, o que os resultados demonstram é que após a adoção das IFRS tal variável (covenants de rating) pode ter deixado de ser um determinante da BTD.

A abordagem de pesquisa pode ser considerada como inovadora, uma vez que não foram encontrados estudos que analisaram a associação das BTD com as cláusulas de rating. Como contribuição teórica, o presente estudo acrescenta as cláusulas de rating como motivadora das ações dos gestores, o que se respalda na teoria contratual da firma, especificamente, quanto à hipótese dos covenants contratuais da perspectiva oportunística. Além disso, o presente estudo acrescenta os covenants de rating no rol de fatores determinantes das BTD. Como contribuição prática, os resultados podem ser úteis às empresas no que se refere a compreender os fatores que podem afetar 0 rating, bem como para as agências de rating quanto a entender as ações dos gestores em busca de cumprir com os covenants de rating.

Como limitações da pesquisa tem-se a obtenção sobre a emissão de títulos de dívida com covenants contratuais de rating, pois, não há essa informação em um banco de dados já organizado. Assim, tal informação foi obtida a partir da leitura das escrituras das debêntures. Outra limitação se refere ao cálculo do lucro tributável a partir da alíquota máxima de imposto de renda do país, uma vez que a alíquota efetiva não é divulgada pelas empresas. Porém, Lev e Nissim (2004) identificaram que o uso da alíquota máxima não afeta o cálculo da BTD de maneira significativa.

Recomenda-se, para futuras pesquisas, investigar a associação entre covenants contratuais de rating e BTD em outros países, bem como testes que abarcam explicações mais detalhadas sobre essa associação, como, por exemplo, ambientes com sistema jurídico diferente, análise por setor e por tipo de BTD.

\section{REFERÊNCIAS}

Adams, M., Burton, B., \& Hardwick, P. (2003). The determinants of credit ratings in the United Kingdom insurance industry. Journal of Business Finance and Accounting, 30(3-4), 539-572. https://doi.org/10.1111/1468-5957.00007 
Ambima - Associação Brasileira das Entidades dos Mercados Financeiro e de Capitais (n.d.). Debêntures. Recuperado em 2018, de http://www.debentures.com.br

Ayers, B. C., Laplante, S. K., \& McGuire, S. T. (2010). Credit ratings and taxes: The effect of book-tax differences on ratings changes. Contemporary Accounting Research, 27(2), 359-402. https://doi.org/10.1111/j.1911-3846.2010.01011.x

Barbosa, J. S. (2019). Book-tax differences e rating, 84. Tese (Doutorado em Ciências Contábeis) - Universidade Federal de Uberlândia, Uberlândia, 2019. Recuperado de https://repositorio.ufu.br/handle/123456789/28704

Barron, M. J., Clare, A. D., \& Thomas, S. H. (1997). The effect of bond rating changes and new ratings on UK stock returns. Journal of Business Finance and Accounting, 24(3-4), 497-509. https://doi.org/10.1111/1468-5957.00117

Barth, M. E., Landsman, W. R., Lang, M. H., \& Williams, C. D. (2012). Are IFRS-based and US GAAP-based Accounting Amounts Comparable? Journal of Accounting \& Economics, 54(1), 68-93. https://ssrn.com/abstract=1585404 or http://dx.doi.org/10.2139/ssrn.1585404

Bis, C., \& Martinez, A.L. (2017). Agressividade fiscal em empresas brasileiras com controle de capital estrangeiro. Encontro da Associação Nacional de PósGraduação e Pesquisa em Administração, São Paulo, SP, Brasil, 41. https://www.researchgate.net/publication/320226522 Agressividade Fiscal em Empresas Brasileiras com Controle de Capital Estrangeiro

Blaylock, B., Gaertner, F., \& Shevlin, T. (2015). The association between book-tax conformity and earnings management. Review of Account Stud, 20(1), 141172. https://doi.org/10.1007/s11142-014-9291-x

Blaylock, B., Gaertner, F. B., \& Shevlin, T. (2017). Book-tax conformity and capital structure. Review of Accounting Studies, 22(2), 903-932. https://doi.org/10.1007/s11142-017-9386-2

Blaylock, B., Shevlin, T., \& Wilson, R. J. (2012). Tax Avoidance, Large Positive Temporary Book-tax differences, and Earnings Persistence. The account review, 87(1), 91-120. https://doi.org/10.2308/accr-10158

Borges, L. F. X. (1999) Covenants: instrumento de garantia em project finance. $\begin{array}{llll}\text { Revista do } & \text { BNDES, } & \text { 13-14. }\end{array}$ http://web.bndes.gov.br/bib/jspui/handle/1408/13823

Bouzouita, R., \& Young, A. J. (1998). A Probit Analysis of Best Ratings. Journal of Insurance Issues, 21 (1), 23-34. https://www.jstor.org/stable/41946150

Burgstahler, D. C., Hail, L., \& Leuz C. (2006). The Importance of Reporting Incentives: Earnings Management in European Private and Public Firms. The Accounting Review, 81 (5), 983-1016. DOlhttps://doi.org/10.2308/accr.2006.81.5.983 
Bushman, R. M., \& Smith, A. J. (2001). Financial Accounting Information and Corporate Governance. Journal of Accounting and Economics, 32 (1-3), 237 - 333. http://dx.doi.org/10.2139/ssrn.253302

Cappellesso, G., \& Rodrigues, J. M. (2019). Book-tax Differences as an Indicator of Earnings Management and Tax Avoidance: An Analysis in the G-20 Countries. Journal of Accounting, Management and Governance, 22 (3), 352-367. http://dx.doi.org/10.21714/1984-3925_2019v22n3a3

Chan, K. H., Lin, Kenny Z. K. Z., \& Mo, P. L. L. (2010). Will a departure from tax-based accounting encourage tax noncompliance? Archival evidence from a transition economy. Journal of Accounting and Economics, 50(1), 58-73. https://doi.org/10.1016/j.jacceco.2010.02.001

Coelho, Antonio C. D., \& Lopes, A. B. (2007). Avaliação da prática de gerenciamento de resultados na apuração de lucro por companhias abertas brasileiras conforme seu grau de alavancagem financeira. Revista de Administração Contemporânea, 11(2), 121-144. https://dx.doi.org/10.1590/S1415-65552007000600007

Comprix, J., Graham, R. C., \& Moore, J. A. (2011). Empirical Evidence on the Impact of Book-tax differences on Divergence of Opinion among Investors. The Journal of the American Taxation Association, 33(1), 51-78. https://doi.org/10.2308/jata.2011.33.1.51

Costa, P. S., \& Lopes, A. B. (2015). Implicações da adoção das IFRS sobre as booktax differences: $O$ caso do Brasil. 1. ed. Alemanha: Novas Edições Acadêmicas.

Costa, P. S., Nakao, S. H., \& Moraes, M. B. (2017). Efeito da suaviação do lucro contábil e do lucro tributável na book-tax differences. Congresso da Associação Nacional de Pós-Graduação em Ciências Contábeis. Belo Horizonte, Minas Gerais, 11.

Crabtree, A., \& Maher, J. J. (2009). The Influence of Differences in Taxable Income and Book Income on the Bond Credit Market. American Accounting Association, 31 (1), 75-99. https://doi.org/10.2308/jata.2009.31.1.75

Desai, M. (2005). The degradation of reported corporate profits. Journal of Economic Perspectives, 19(4), 171-192. https://doi.org/10.2307/2225251

Edwards, A., Schwab, C., \& Shevlin, T. (2016). Financial constraints and cash tax savings. The Accounting Review, 91 (3), 859-881. https://doi.org/10.2308/accr51282

Ferreira, F. R., Martinez, A. L., Costa, F. M., \& Passamani, R. Rovetta. (2012). Booktax differences e gerenciamento de resultados no mercado de ações do Brasil. Revista de Administração de Empresas, 52(5), 488-501. https://dx.doi.org/10.1590/S0034-75902012000500002 
Fonseca, K. B., \& Costa, P. S. (2017). Fatores determinantes das book-tax differences. Journal of Accounting and Organizations, 11(2), 17-29. http://dx.doi.org/10.11606/rco.v11i29.122331

Frank, M. M, Lynch, L. J., \& Rego, S. O. (2009). Tax Reporting Aggressiveness and Its Relation to Aggressive Financial Reporting. The Accounting Review, 84(2), 467496. http://dx.doi.org/10.2308/accr.2009.84.2.467

Gomes, A. P. M. (2016). Corporate Governance Characteristics as a Stimulus to Tax Management. Revista Contabilidade \& Finanças, 27(71), 149-168. https://dx.doi.org/10.1590/1808-057x201500750

Gray, S., Mirkovic, A., \& Ragunathan, V. (2006). The Determinants of Credit Ratings: Australian Evidence. Australian Journal of Management, 31(2), 333-354. https://doi.org/10.1177/031289620603100208

Han, S. H., Shin, Y. S., Reinhart, W., \& Moore, W. T. (2009). Market segmentation effects in corporate credit rating changes: The case of emerging markets. Journal of Financial Services Research, 35(2), 141-166. https://doi.org/10.1007/s10693-008-0049-0

Hanlon, M. (2005). The presister and pricing of earnin accruals and cash flows when firms have book-tax differences. The Accounting Review, 80(1), 137-166. https://doi.org/10.2308/accr.2005.80.1.137

Huang, D., \& Chang, M. (2015). Do auditor-provided tax services improve the relation between tax related internal control and book-tax differences?. AsiaPacific Journal of Accounting \& Economics, 23(2), 177-199. http://dx.doi.org/10.1080/16081625.2014.1003570

Kaymak, T., \& Bektas, E. (2015). Corruption in Emerging Markets: A Multidimensional Study. Social Indicators Research, 124(3), 1-21. http://doi.org/10.1007/s1 1205014-0814-4

Kisgen, D. J. (2006). Credit Ratings and Capital Structure. The Journal of Finance, 61 (3), 1035-1072. https:// http://doi.org/10.1111/j.1540-6261.2006.00866.x

Kothari, S. P., Leone, A. J., \& Wasley, C. E. (2005). Performance matched discretionary accrual measures. Journal of Accounting and Economics, 39(1), 163-197. https://doi.org/10.1016/j.jacceco.2004.11.002

Koubaa, R., \& Anis, A. (2015). Book-tax differences: relevant explanatory factors. International Journal of Accounting and Economics Studies, 3(2), 95-104. https://doi.org/10.14419/ijaes.v3i2.4717

Long, Y., Kangtao, Y., \& LV, M. (2013). Non-institutional Determinants of Book-Tax Differences: Evidence from China. Journal of Accounting and Finance, 13(3), 146-153. http://www.na-businesspress.com/JAF/LongY_Web13_3_.pdf 
Manzon, G. B., \& Plesko, G. A. (2002). The relation between financial and tax reporting measures of income. Massachusetts Institute of Technology (MIT), Sloan School of Management, Working papers, 55 (2), 175-214. http://dx.doi.org/10.2139/ssrn.264112

Marques, M., \& Nakao, S.H. (2017). Book-tax differences and capital structure. Mackenzie Management Review, 18(6), 177-200. https://doi.org/10.1590/1678-69712017/administracao.v18n6p177-200.

Martinez, A. L., \& Passamani, R. R. (2014). Book-tax differences e sua relevância informacional no mercado de capitais no brasil. Revista de Gestão, Finanças e Contabilidade, 4(2), 20-37. http://dx.doi.or/10.180828/rgfc.v4i2.615.

Miiller, D., \& Martinez, A. (2016). Book-tax difference, earnings management and bond ratings in the brazilian market. Revista Universo Contábil, 91-109. https://doi.org/10.4270/ruc.2016323

Moore, J. A. (2012). Empirical evidence on the impact of external monitoring on book-tax differences. Advances in Accounting, 28(2), 254-269. https://doi.org/10.1016/j.adiac.2012.06.002

Murcia, F. C. (2013). Rating de crédito no brasil: Fatores Determinantes e Impacto de Anúncios nos Preços das Ações, 153. Recuperado de https://repositorio.ufsc.br/bitstream/handle/123456789/107160/318126.pdf?s equence= 1 \&isAllowed=y

Nakao, S. (2012). A adoção de IFRS eo legado da conformidade contábil-fiscal mandatória. Teses.Usp.Br. Recuperado de http://www.teses.usp.br/teses/disponiveis/livredocencia/96/tde-31012014140349/en.php

Pinto, L. J., Falcão, D. F., \& Mól, A. R. (2015). Emissão de debêntures e seu impacto nos indicadores de desempenho e financeiro: Um estudo comparativo entre empresas emissoras e não emissoras. Revista de Auditoria Governança e Contabilidade, 3(8), 1-16. http://www.fucamp.edu.br/editora/index.php/ragc/article/view/613/452

Soares, G. de O. G., Coutinho, E. S., \& Camargos, M. A. de. (2012). Determinantes do Rating de Crédito de Companhias Brasileiras. Contabilidade Vista \& Revista, 23(3), 109-143. https://doi.org/10.1017/СВO9781 107415324.004

Tang, T. Y. H. (2005). Book-tax differences, a Proxy for Earnings Management and Tax Management - Empirical Evidence from China. SSRN Electronic Journal. https://doi.org/10.2139/ssrn.872389

Tang, T.Y.H. (2014). Does Book-Tax Conformity Deter Opportunistic Book and Tax Reporting? An International Analysis. European Accounting Review, 24(3), 441 469. https://doi.org/10.1080/09638180.2014.932297 
Watts, R. L., \& Zimmerman, J. L. (1990). Positive Accounting Theory: A Ten Year Perspective. The Accounting Review, 65(1), 131-156. https://www.jstor.org/stable/247880

Weber, D. P. (2009). Do analysts and investors fully appreciate the implications of book-tax differences for future earnings? Contemporary Accounting Research, 26(4), 1175-1206. https://doi.org/10.1506/car.26.4.7

Wilson, R. J. (2009). An examination of corporate tax shelter participants. Accounting Review, 84(3), 969-999. https://doi.org/10.2308/accr.2009.84.3.969

Xian, C., Sun, F., \& Zhang, Y. (2015). Book-tax differences: are they affected by equity-based compensation? Accounting Research Journal, 28(3),300-318. https://doi.org/10.1108/ARJ-12-2013-0088 